This item was submitted to Loughborough's Research Repository by the author.

Items in Figshare are protected by copyright, with all rights reserved, unless otherwise indicated.

\title{
The accumulation of exercise and postprandial endothelial function in boys
}

PLEASE CITE THE PUBLISHED VERSION

http://dx.doi.org/10.1111/sms.12101

PUBLISHER

(c) John Wiley and Sons

VERSION

AM (Accepted Manuscript)

LICENCE

CC BY-NC-ND 4.0

REPOSITORY RECORD

Sedgwick, Matthew J., John G. Morris, Mary Nevill, and Laura A. Barrett. 2019. "The Accumulation of Exercise and Postprandial Endothelial Function in Boys”. figshare. https://hdl.handle.net/2134/21894. 
The accumulation of exercise and postprandial endothelial function in boys

Running head: The accumulation of exercise in boys

Matthew J. Sedgwick ${ }^{1}$, John G. Morris ${ }^{1}$, Mary E. Nevill ${ }^{1}$ and Laura A. Barrett ${ }^{1}$

${ }^{1}$ Institute of Youth Sport, School of Sport, Exercise and Health Sciences, Loughborough University, Loughborough, LE11 3TU, UK

\section{Conflicts of interest and sources of funding: None}

\section{Corresponding author}

Dr. Laura Barrett

School of Sport, Exercise and Health Sciences

Loughborough University

Loughborough

Leicestershire

LE11 3TU

UK.

푱 + 441509226395

悬 + 441509226301

品 L.A.Barrett@1boro.ac.uk 


\begin{abstract}
The purpose of this study was to investigate the effect of accumulating $60 \mathrm{~min}$ of exercise on endothelial function and triacylglycerol concentrations following the ingestion of a high-fat breakfast and lunch in fourteen adolescent boys (aged 12 to 14 years). Two, 2-day main trials (control and exercise) were completed in a counter-balanced, cross-over design. Participants were inactive on day 1 of the control trial but on day 1 of the exercise trial completed $6 \times 10$ min runs at $70 \%$ of peak oxygen uptake, spread over the day. On day 2 triacylglycerol concentrations and flow-mediated dilation (FMD) were measured prior to, and following, ingestion of the high-fat meals. In the control trial FMD was reduced by $30 \%$ and $33 \%$ $(\mathrm{P}<0.001)$ following the high-fat breakfast and lunch; following exercise these reductions were negated (main effect trial, $\mathrm{P}=0.002$, interaction effect trial $\mathrm{x}$ time, $\mathrm{P}<0.001$ ). The total and incremental areas under the triacylglycerol concentration versus time curve were reduced by $11 \%$ and $16 \%$ in the exercise trial; however, these differences were not significant $(\mathrm{P}>0.05)$. These results support the concept of accumulating physical activity for health in adolescents as the accumulated exercise attenuated the decline in FMD seen following the consumption of high-fat meals.
\end{abstract}

Keywords: Flow-mediated dilation; Postprandial lipemia; Triacylglycerol; Cardiovascular disease risk. 


\section{Introduction}

Coronary heart disease does not typically manifest until adulthood; however, the process leading to coronary heart disease, atherosclerosis, is a chronic, progressive disease with its origins in childhood (Strong and Gill, 1962). The development and progression of atherosclerosis is reliant on the presence of a high coronary heart disease risk profile (Magnussen et al., 2012). Endothelial dysfunction and high triacylglycerol concentrations, particularly postprandial triacylglycerol concentrations, have been implicated in the development and progression of atherosclerosis (Zilversmit, 1979; Ross, 1999; Juonala et al., 2004) and identified as independent risk factors for coronary heart disease (Bansal et al., 2007; Yeboah et al., 2009). The consumption of a meal containing substantial quantities of fat is common in western societies (Taveras et al., 2005) and results in a transient state of endothelial dysfunction and elevated triacylglycerol concentrations (Vogel et al., 1997; Wallace et al., 2010; Sedgwick et al., 2012). Therefore, interventions that attenuate postprandial endothelial dysfunction and lower triacylglycerol concentrations, even in the young, may slow or delay atherogenesis and ultimately have important health benefits.

Current physical activity guidelines (60 min of moderate to vigorous-intensity physical activity daily for children and adolescents) indicate that the recommended volume of physical activity does not need to be undertaken in a single, continuous bout but can be accumulated, over the day, in multiple bouts of shorter duration (World Health Organization, 2010). Experimental research supporting this concept of accumulating activity in the young is at best sparse. However, such an activity pattern may be particularly suitable for the young, as young people's activity bouts are typically spontaneous and of a short duration (Stone et al., 2009) and also the young are known to perceive prolonged exercise to be more demanding than adults (Timmons et al., 2003). Consequently, accumulating physical activity in multiple short-duration bouts over a day may not just be suitable, but also an appealing activity pattern for the young.

Previous research has observed that a single session of continuous moderate-intensity walking or running, completed 14 to 16 hours before the ingestion of a high-fat meal, can attenuate postprandial endothelial dysfunction and lower postprandial triacylglycerol concentrations in both adults (Gill et al., 2004; Tyldum et al., 2009) and adolescents (Sedgwick et al., 2012). Research in adults also suggests that the reductions in postprandial triacylglycerol concentrations in the day following exercise are similar regardless of whether the exercise was 
completed in a single session or accumulated over multiple, short-duration sessions spread throughout a day (Gill et al., 1998; Miyashita et al., 2006; Miyashita et al., 2008). The effect of accumulating exercise in children or adolescents on postprandial triacylglycerol concentrations has yet to be investigated. Furthermore, no study has investigated the effect of accumulating exercise on postprandial endothelial dysfunction in adults, adolescents or children.

Therefore the purpose of this study was to investigate if accumulating $60 \mathrm{~min}$ of running could attenuate postprandial endothelial dysfunction and lower postprandial triacylglycerol concentrations in adolescent boys.

\section{Methods}

\section{Participants}

Seventeen recreationally active adolescent boys volunteered to participate in the study, with fourteen boys completing the study (aged 12.1 to 14.4 years). Non-completion of the study was due to signs and symptoms of presyncope during blood sampling $(n=3)$. The study was conducted according to the guidelines laid down in the Declaration of Helsinki and all procedures were approved by Loughborough University Ethical Advisory Committee. Before any testing took place all participants had the procedures and risks associated with involvement in the study explained to them. Written consent from a parent and written assent from each participant was then obtained. All participants were apparently healthy and not taking any drugs known to affect lipid or carbohydrate metabolism. The physical characteristics of those who completed the study are shown in Table 1.

\section{Study Design}

Participants completed preliminary tests and then undertook two, 2-day main trials which were separated by seven days (a control trial and an exercise trial) in a 2 x 2 replicated Latin square design. 


\section{Preliminary Tests}

Height and sitting height were measured to the nearest $0.1 \mathrm{~cm}$ using a wall mounted stadiometer (Seca, Germany), body mass was measured to the nearest $0.01 \mathrm{~kg}$ using a beam balance scale (Avery, Birmingham, UK) and age from peak height velocity was estimated (Mirwald et al., 2002). Skinfold thicknesses were measured to the nearest $0.2 \mathrm{~mm}$ at four sites (biceps, triceps,

subscapular and suprailiac) using Harpenden callipers (Baty International, England). All measurements were taken from the right-hand side of the body, with the median of three measures taken to be the skinfold thickness. Waist and hip circumferences were measured to the nearest $0.1 \mathrm{~cm}$. A self-assessment of maturity, based on secondary sexual characteristics, was completed (Tanner, 1989).

Following anthropometric measures participants completed two exercise tests performed on a motorised treadmill (Runner Galaxy M.J.C., MTC Climb 2000, Bianchiah and Draghetti Sac, Cavezzo, Italy). Firstly, a 16-min, 4-stage, sub-maximal treadmill test was completed in order to determine the relationship between running speed and oxygen uptake. The speed was set at $7 \mathrm{~km} \cdot \mathrm{h}^{-1}$ for the first stage of this test and set at an incline of $1 \%$. The treadmill speed increased by $1 \mathrm{~km} \cdot \mathrm{h}^{-1}$ every stage. Participants then rested for $60 \mathrm{~min}$ and following this completed an incremental uphill treadmill test until volitional fatigue to determine peak oxygen uptake $\left(\dot{\mathrm{VO}}_{2}\right.$ peak). The speed was set at that which elicited a heart rate of 170 beats $\cdot \mathrm{min}^{-1}$ during the sub-maximal test and at an initial incline of $3 \%$. Treadmill incline increased by $2 \%$ every 3 min. During these exercise tests heart rate was recorded using short-range telemetry (Polar, Finland), ratings of perceived exertion were assessed using the Borg scale (Borg, 1973) and expired air samples collected and analysed (Williams and Nute, 1983) in the final minute of each stage and the final minute of the peak oxygen uptake test.

\section{Main trials}

Participants were instructed not to consume alcohol or supplements in the seven days before and throughout each main trial. Participants recorded all food and drinks consumed during the day before (day 0 ) and day 1 of the first main trial and were asked to replicate this diet prior to the subsequent trial. Participants were also instructed to refrain from any physical activity, except that prescribed by the investigators, on day 0 and throughout each main trial. During 
this time participants wore an ActiGraph GT1M accelerometer during waking hours to monitor physical activity. The ActiGraph is a uniaxial electromechanical device that records movement in the vertical plane. The sampling epoch was 5 seconds. During data processing 60 minutes of consecutive zero's was considered indicative of non-wearing and these data were excluded. Minimum day length was set at 9 hours and time spent in low- and moderate- and vigorousintensity physical activity was calculated using age specific cutpoints (Freedson et al., 1997) and daily energy expenditure estimated using previously published equations (Trost et al., 1998).

On day 1 of the control trial participants were instructed to be as physically inactive as possible and to refrain from any form of exercise whilst in their free-living environment, whereas in the exercise trial they reported to the laboratory at 09:00 and completed $6 \times 10$ min runs on a treadmill at $70 \%$ of $\mathrm{VO}_{2}$ peak. Each run was followed by 50 min of rest. The first run began at 09:30 resulting in the final run ceasing at 14:40. Heart rate, ratings of perceived exertion and expired air samples were collected in the last minute of each run. Energy expenditure was estimated using indirect calorimetry (Frayn, 1983). On leaving the laboratory after the last run the participants reminded to be as physically inactive as possible and to refrain from any form of exercise whilst in their free-living environment.

On day 2 of each main trial participants reported to the laboratory at 08:00, following an overnight fast, where flow-mediated dilation (FMD) was assessed and a capillary blood sample collected $(0 \mathrm{~h})$. Participants then ate breakfast at 08:40 and a clock was started on commencement of the meal. After breakfast participants rested for $6.5 \mathrm{~h}$ in the laboratory with lunch provided at $3.5 \mathrm{~h}$. FMD was assessed again at 3 and $6.5 \mathrm{~h}$ and additional blood samples collected at $0.5,1,3,4,4.5$ and $6.5 \mathrm{~h}$.

\section{Meals}

Breakfast consisted of croissant, chocolate spread and a chocolate milkshake (chocolate power, whole-fat milk and double cream), providing $1.5 \mathrm{~g}$ fat (60\%), $1.8 \mathrm{~g}$ carbohydrate (33\%), $0.4 \mathrm{~g}$ protein $(7 \%)$ and $93 \mathrm{~kJ}$ per kilogram body mass. Participants were given 15 min to consume breakfast. Lunch consisted of a cheese sandwich (white bread, butter and cheese), ready salted potato-chips and a chocolate milkshake (chocolate powder and whole-fat milk), providing 1.1 
$\mathrm{g}$ fat $(50 \%), 1.9 \mathrm{~g}$ carbohydrate (37\%), $0.6 \mathrm{~g}$ protein (13\%) and $85 \mathrm{~kJ}$ per kilogram of body mass. Participants were given $20 \mathrm{~min}$ to consume lunch. Participants consumed water ad libitum during the first trial and any intake was replicated in the subsequent trial.

\section{Endothelial function assessment by flow-mediated dilation}

The methods used to assess FMD have previously been reported (Corretti et al., 2002; Thijjsen et al., 2011; Sedgwick et al., 2012). Briefly, a high-resolution ultrasound (Power Vision 6000, Toshiba, Tochigi, Japan) with a $11 \mathrm{MHz}$ linear array transducer was used to image the brachial artery in a longitudinal section in the distal third of the upper right arm. Ultrasound settings (gain, focus zone and depth) were set to optimise longitudinal B-mode images of the lumenarterial wall interface. Pulsed wave Doppler was used, simultaneously with B-mode imaging, to assess blood flow velocity. Following $20 \mathrm{~min}$ of supine rest, a series of images were collected both before (over $30 \mathrm{~s}$ ) and after (over $180 \mathrm{~s}$ ) $5 \mathrm{~min}$ of forearm ischemia. All images were captured on the r-wave of the cardiac cycle and then stored electronically for later analysis. Recorded images were digitised using specialised edge-detection and wall-tracking software (Brachial analyzer, version 4.1.3; Medical Imaging Applications LLC, Iowa City, IA). FMD was calculated as the percentage change from basal diameter to peak diameter, and was also normalised for the post-occlusion shear rate using the area under the shear rate versus time curve (between cuff release and peak diameter) (Harris et al., 2010).

Ultrasound settings were standardised, for each participant, for every subsequent measurement. Measurement location was also standardised for each participant based on anatomical landmarks, snapshot images and an ink marker placed on the skin that was maintained between trials. The $\mathrm{CV}$ of measurements made seven days apart for fasting basal diameter and FMD in our laboratory were 0.6 and $9.7 \%$, and in the postprandial state were 0.8 and $10.0 \%$ respectively. 


\section{Blood sampling and biochemical analysis}

Capillary blood samples were collected, from a warmed left hand, into $500 \mu \mathrm{l}$ potassiumEDTA-coated microvettes (Sarstedt, Leicester, UK) and immediately centrifuged at $1500 \mathrm{x} \mathrm{g}$ for $10 \mathrm{~min}$ at $4{ }^{\circ} \mathrm{C}$. The resulting plasma was then stored at $-20{ }^{\circ} \mathrm{C}$ for later analysis. Plasma triacylglycerol and glucose concentration were determined by enzymatic, colorimetric methods (HORIBA ABX Diagnostics, Montpellier, France) and plasma insulin concentration was determined by ELISA (Mercodia, Uppsala, Sweden). Within batch CV's were: triacylglycerol $1.2 \%$, glucose $0.5 \%$ and insulin $8.8 \%$.

\section{Statistical analysis}

Data was analysed using the PASW statistics software version 18.0 for Windows (SPSS Inc, Chicago, IL). The total and incremental (after correcting for fasting concentrations) areas under the plasma concentration versus time curves for triacylglycerol, glucose and insulin were calculated using the trapezium rule. Insulin resistance was evaluated according to the homeostatic model assessment of insulin resistance (HOMA-IR) (Matthews et al., 1985). Residual errors were tested for normality using the Shapiro-Wilk test, where necessary data was logarithmically transformed prior to statistical analysis. Time spent in low and moderateto-vigorous intensity physical activity during day 0 and day 1 of the main trials were compared between trials using paired Student's t-test. Fasting basal diameter, peak diameter, the area under the shear rate versus time curve, FMD, normalised FMD and plasma triacylglycerol, glucose and insulin concentration and the areas under the plasma concentration versus time curves were compared between trials using paired Student's $t$-test. A mixed effects general linear model with two fixed factors (trial and time) and one random factor (participant) was used to compare differences between trials over time, and any possible interactions between trial and time, for basal diameter, peak diameter, the area under the shear rate versus time curve, FMD, normalised FMD and plasma triacylglycerol, glucose and insulin concentration. Least significant difference post-hoc analysis was used to identify where any significant effects of time lay. When a significant trial $\mathrm{x}$ time interaction was revealed targeted pair wise comparisons were used, specifically, comparisons within-trial with respect to the fasting measure and between-trials at the same time point. Pearson's correlation coefficient was calculated in the control and in the exercise trial: for fasting plasma triacylglycerol 
concentration and fasting FMD; for the change in FMD and the total area under the plasma triacylglycerol concentration versus time curve from $0 \mathrm{~h}$ to $3 \mathrm{~h}$; for the change in FMD and the total area under the plasma triacylglycerol concentration versus time curve from $0 \mathrm{~h}$ to $6.5 \mathrm{~h}$; for basal diameter and fasting FMD; for the change in FMD and basal diameter from $0 \mathrm{~h}$ to 3 $\mathrm{h}$; and for the change in FMD and basal diameter from $0 \mathrm{~h}$ to $6.5 \mathrm{~h}$ (twelve correlations in total). Statistical significance was accepted as $\mathrm{P}<0.05$. All participant characteristics are presented as population marginal means and standard deviations (SD) and experimental data are presented as population marginal means and standard error of the mean (SEM).

\section{$\underline{\text { Results }}$}

\section{Physical activity}

Complete accelerometer data was provided by ten boys. One boy and three boys did not provide data for day 0 in the control and exercise trial, respectively. During day 0, no differences were observed between trials in the time spent in low-, moderate- and vigorousintensity physical activity (Table $2 ; \mathrm{P}=0.605, \mathrm{P}=0.516$ and $\mathrm{P}=0.848$, respectively). During day 1 less time was spent in low- and moderate-intensity and more in vigorous-intensity physical activity in the exercise trial compared to the control trial (Table 2; all $\mathrm{P}<0.001$ ). During day 0 energy expenditure was not different between trials, but during day 1 energy expenditure was $1.13 \pm 0.77 \mathrm{MJ}$ greater during the exercise trial compared to the control trial (Table 2; $\mathrm{P}=0.294$ and $\mathrm{P}<0.001$, respectively).

\section{Responses to treadmill exercise}

The six, 10 min bouts of running elicited a mean heart rate, ratings of perceived exertion and oxygen uptake of $169 \pm 4$ beats $\cdot \mathrm{min}^{-1}, 13 \pm 1$ and $32.6 \pm 1.5 \mathrm{ml} \cdot \mathrm{kg}^{-1} \cdot \mathrm{min}^{-1}(72 \pm 2 \%$ of participants $\dot{\mathrm{VO}}_{2}$ peak) respectively. The gross energy expenditure of the total exercise protocol (6 x $10 \mathrm{~min}$ ) was $1.90 \pm 0.08 \mathrm{MJ}$ or $39.2 \pm 1.7 \mathrm{~kJ} \cdot \mathrm{kg}^{-1}$ body mass. 


\section{Basal diameter, peak diameter, flow-mediated dilation and normalised flow-mediated dilation}

No differences were observed between trials for fasting basal diameter (Table 3, $\mathrm{P}=0.477$ ), peak diameter (Table 3, $\mathrm{P}=0.650$ ), the area under the shear rate versus time curve (Table 3, $\mathrm{P}$ $=0.577$ ), FMD (Fig 1 (a), P = 0.664) and normalised FMD (Fig 1 (b), P = 0.329).

Basal diameter, peak diameter and the area under the shear rate versus time curve, increased following the ingestion of the high-fat meals, but no differences were evident between trials (Table 3; basal diameter: main effect trial, $\mathrm{P}=0.178$; main effect time, $\mathrm{P}<0.001$; interaction effect trial $\mathrm{x}$ time, $\mathrm{P}=0.088$; peak diameter: main effect trial, $\mathrm{P}=0.524$; main effect time, $\mathrm{P}=$ 0.004; interaction effect trial $\mathrm{x}$ time, $\mathrm{P}=0.972$; the area under the shear rate versus time curve: main effect trial, $\mathrm{P}=0.982$; main effect time, $\mathrm{P}<0.001$; interaction effect trial $\mathrm{x}$ time, $\mathrm{P}=$ $0.572)$.

Postprandial FMD was lower in the control compared with the exercise trial both before (Fig 1(a); main effect trial, $\mathrm{P}=0.004$; main effect time, $\mathrm{P}<0.001$; interaction effect trial $\mathrm{x}$ time, $\mathrm{P}$ $<0.001$ ) and after normalisation for the post-occlusion shear rate (Fig 1(b); main effect trial, $\mathrm{P}$ $=0.020$; main effect time, $\mathrm{P}<0.001$; interaction effect trial $\mathrm{x}$ time, $\mathrm{P}=0.014)$. Pairwise comparisons revealed that FMD, both before and after normalisation for the post-occlusion shear rate, was significantly lower than the fasting measure at both $3 \mathrm{~h}(\mathrm{P}<0.001)$ and $6.5 \mathrm{~h}$ $(\mathrm{P}<0.001)$ in the control trial only. Pairwise comparisons also revealed that FMD, both before and after normalisation, was significantly higher in the exercise trial compared to the control trial at $3 \mathrm{~h}(\mathrm{P}<0.001$ and $\mathrm{P}=0.048)$ and $6.5 \mathrm{~h}(\mathrm{P}<0.001$ and $\mathrm{P}=0.002)$.

\section{Triacylglycerol, glucose and insulin concentrations}

No differences were observed between trials for fasting plasma triacylglycerol concentration (Fig 2 (a), $\mathrm{P}=0.706$ ), plasma glucose concentration (Fig 2 (b), $\mathrm{P}=0.471$ ) and plasma insulin concentration (Fig 2 (c), $\mathrm{P}=0.656$ ). No differences were observed between trials for fasting HOMA-IR (Control vs. Exercise: $1.6 \pm 0.3$ vs. $1.5 \pm 0.2, \mathrm{P}=0.625$ ).

Postprandial plasma triacylglycerol concentrations did not differ between trials (Fig 2(a); main effect trial, $P=0.385$; main effect time, $P<0.001$; interaction effect trial $\mathrm{x}$ time, $P=0.091$ ). 
The total area under the plasma triacylglycerol concentration versus time curve was $11 \%$ lower on average in the exercise compared to the control trial; however, this did not reach statistical significance (Control vs. Exercise: $10.71 \pm 0.94$ ) vs. $9.56 \pm 0.67$ ) $\mathrm{mmol} \cdot \mathrm{L}^{-1} \cdot 6.5 \mathrm{~h}$, respectively, $P=0.183)$. The incremental area under the plasma triacylglycerol concentration versus time curve was $16 \%$ lower in the exercise compared to the control trial, however this did not reach statistical significance (Control vs. Exercise: $6.13 \pm 0.63$ vs. $5.14 \pm 0.41 \mathrm{mmol} \cdot \mathrm{L}^{-1} \cdot 6.5 \mathrm{~h}$, respectively, $P=0.088)$.

Postprandial plasma glucose concentrations did not differ between trials (Fig 2(b); main effect trial, $P=0.916$; main effect time, $P<0.001$; interaction effect trial $\mathrm{x}$ time, $P=0.066$ ). No difference was observed between the control and exercise trial for the total area under the plasma glucose concentration versus time curve (Control vs. Exercise: $41.17 \pm 0.79$ vs. 41.32 $\left.\pm 0.84 \mathrm{mmol} \cdot \mathrm{L}^{-1} \cdot 6.5 \mathrm{~h}, P=0.741\right)$.

Postprandial plasma insulin concentrations did not differ between trials (Fig 2(c); main effect trial, $P=0.435$; main effect time, $P<0.001$; interaction effect trial $\mathrm{x}$ time, $P=0.515$ ). No difference was observed between the control and exercise trial for the total area under the plasma insulin concentration versus time curve (Control vs. Exercise: $1685.4 \pm 207.6$ vs. $\left.1642.2 \pm 255.0 \mathrm{pmol} \cdot \mathrm{L}^{-1} \cdot 6.5 \mathrm{~h}, P=0.271\right)$.

\section{Correlations between flow-mediated dilation and basal diameter and triacylglycerol concentrations.}

The correlations between fasting FMD and fasting plasma triacylglycerol concentrations were: Control, $\mathrm{r}=0.062, \mathrm{P}=0.841$; Exercise, $\mathrm{r}=-0.347, \mathrm{P}=0.245$. The correlations between the change in FMD and the total area under the plasma triacylglycerol concentration versus time curve from $0 \mathrm{~h}$ to $3 \mathrm{~h}$, were: Control, $\mathrm{r}=-0.073, \mathrm{P}=0.812$; Exercise, $\mathrm{r}=-0.133, \mathrm{P}=0.666$. The correlations between the change in FMD and the total area under the plasma triacylglycerol concentration versus time curve from $0 \mathrm{~h}$ to $6.5 \mathrm{~h}$, were: Control, $\mathrm{r}=-0.295, \mathrm{P}=0.328$; Exercise, $\mathrm{r}=-0.342, \mathrm{P}=0.253$.

The correlations between fasting FMD and fasting basal diameter were: Control, $r=-0.653$, $\mathrm{P}=0.016$; Exercise, $\mathrm{r}=-0.554, \mathrm{P}=0.049$. The correlations between the change in FMD and basal diameter from $0 \mathrm{~h}$ to $3 \mathrm{~h}$, were: Control, $\mathrm{r}=-0.244, \mathrm{P}=0.422$; Exercise, $\mathrm{r}=0.396, \mathrm{P}=0.181$. 
The correlations between the change in FMD and basal diameter from $0 \mathrm{~h}$ to $6.5 \mathrm{~h}$, were: Control, $r=-0.218, P=0.473$; Exercise, $r=-0.243, P=0.424$.

\section{$\underline{\text { Discussion }}$}

The main finding of the present study was that, for adolescent boys, accumulating $60 \mathrm{~min}$ of exercise in short bouts throughout a day, before the consumption of a high-fat breakfast and lunch, attenuated the postprandial decline in FMD seen in the control trial. The total and incremental areas under the triacylglycerol concentration versus time curve were reduced by $11 \%$ and $16 \%$ respectively when the accumulated exercise trial was compared with the control, although these differences were not statistically significant.

In the present study postprandial endothelial dysfunction was evident in the control trial following breakfast and lunch with FMD being reduced, compared to fasting, by 30 and 33\% respectively (both $P<0.05$ ). This postprandial endothelial dysfunction following food ingestion has been seen previously in both adults (Vogel et al., 1997; Gill et al., 2003; Gill et al., 2004; Wallace et al., 2010) and adolescents (Sedgwick et al., 2012). When the adolescent boys in the present study accumulated $60 \mathrm{~min}$ of exercise in short bouts $(6 \mathrm{x} 10 \mathrm{~min}$ of treadmill running at $70 \% \dot{\mathrm{VO}}_{2}$ peak), accumulated the day before the ingestion of a high-fat breakfast and lunch, the postprandial endothelial dysfunction seen in the control trial was not apparent as fasting FMD and postprandial FMD in the exercise trial were similar. This finding is consistent with previous studies that used a longer continuous bout of prior exercise rather than the shorter accumulated bouts used in the present study (Gill et al., 2004; Tyldum et al., 2009; Sedgwick et al., 2012). When FMD was normalised, for the area under the shear rate vs. time curve, the postprandial decline in FMD was still evident in the control trial and again the accumulated exercise attenuated this decline. Therefore, the results from this study demonstrate for the first time, that accumulating $60 \mathrm{~min}$ of exercise in short bouts throughout a day is effective at attenuating postprandial endothelial dysfunction, at least in adolescent boys.

The six short bouts of exercise accumulated the day before the ingestion of the high-fat breakfast and lunch also attenuated postprandial triacylglycerol responses, with the total and incremental areas under the triacylglycerol concentration versus time curve reduced by $11 \%$ and $16 \%$ respectively when the exercise trial was compared with the control, although these 
differences were not statistically significant $(P=0.183$ and $P=0.088$ respectively). In previous studies involving adolescents' prior continuous moderate-intensity exercise reduced total and incremental area by 14-22\% and 5-38\% respectively (Barrett et al., 2007; Tolfrey et al., 2008; MacEneaney et al., 2009; Sedgwick et al., 2012; Tolfrey et al., 2012), so the findings from the present study seem consistent with those previously seen. In adults $30 \mathrm{~min}$ of prior moderateintensity exercise, undertaken either in a single bout or accumulated over short bouts throughout a day, proved equally effective at significantly lowering postprandial triacylglycerol concentrations (Miyashita et al., 2006; Miyashita et al., 2008). In the present study, despite the changes in postprandial triacylglycerol concentrations induced by the prior accumulated exercise not reaching statistical significance, the reduction in the total and incremental area under the triacylglycerol concentration versus time curve is in line with previous research in adolescents, and may still be meaningful and have physiological importance.

At present there are no defined clinical cut-off points for postprandial triacylglycerol concentrations, making it challenging to define a clinically important change. However, it is recognised that minimum clinically important changes are needed to determine whether experimental changes are meaningful. Nordestgaard and colleagues (2007) and Langested and colleagues (2011) reported, in prospective studies, that men with a postprandial triacylglycerol concentration between 1.00 and 1.99 mmol. $\mathrm{L}^{-1}$ were 30 to $40 \%$ more likely to experience myocardial infarction and $10 \%$ more likely to experience ischemic heart disease than men with a postprandial triacylglycerol concentration of less than 1 mmol. $\mathrm{L}^{-1}$. In addition, beyond these concentrations, greater postprandial triacylglycerol concentrations were associated with even greater risk of developing myocardial infarction and ischemic heart disease. Therefore, it would appear that any reduction in postprandial triacylglycerol concentrations can reduce the risk of future coronary heart disease, suggesting that the reductions in triacylglycerol concentrations seen in the present study, following exercise the day before ingestion of the high fat meals, while not statistically significant, were likely to be meaningful. Furthermore, the importance of maintaining low postprandial triacylglycerol concentrations during adolescence was highlighted by Morrison and colleagues (2009) where adolescents with high postprandial triacylglycerol concentrations were more likely to experience cardiovascular disease in the fourth and fifth decade of life.

Analysis of the accelerometer data collected in the two days preceding the day when the highfat meals were consumed, undertaken to confirm the physical activity levels of the study's 
participants, demonstrated that the time spent in low-, moderate- and vigorous-intensity physical activity was not different during day 0 of the control and exercise trials. During day 1 of the exercise trial the boys did spend more time in vigorous-intensity physical activity, as would have been expected, but they actually spent less time in low- and moderate-intensity physical activity than in the control trial (see Table 2). Consequently, although the boys expended $1.90 \pm 0.08 \mathrm{MJ}$ during the prescribed exercise, the estimated difference in total daily energy expenditure between the exercise and control trials was substantially less than this (estimated to be $1.1 \pm 0.8 \mathrm{MJ}$ greater on day 1 of the exercise trial compared with day 1 of the control trial). Therefore, although the participants were instructed to be as physically inactive as possible and to refrain from any form of exercise whilst in their free-living environment, their adherence to these instructions, perhaps not unexpectedly, was poorer under free-living conditions compared with that achieved in the more controlled laboratory conditions where physical inactivity was ensured.

The smaller than expected net increase in energy expenditure may have influenced the participant's triacylglycerol responses in the present study. Previous research in adults suggests that the effect of prior exercise on postprandial triacylglycerol concentrations is dependent on the energy expended (Petitt et al., 2003). Maraki and Sidossis have argued that an expenditure of at least $2.0 \mathrm{MJ}$ is required to observe any reduction in postprandial triacylglycerol concentrations (Maraki and Sidossis, 2010), although prior moderate-intensity exercise has been shown to lower postprandial triacylglycerol concentrations when the energy expended has been below 2.0 MJ (Peddie et al., 2012). Recent work in adolescents has failed to establish that energy expenditure per se is the primary determinant of attenuated postprandial triacylglycerol concentrations. Tolfrey and colleagues $(2008,2012)$ reported similar reductions in postprandial triacylglycerol concentrations in adolescent boys when 60 min of running at $53 \%$ or $75 \% \dot{\mathrm{VO}}_{2}$ peak (Tolfrey et al., 2008) and $30 \mathrm{~min}$ or $60 \mathrm{~min}$ of running at $55 \% \mathrm{VO}_{2}$ peak (Tolfrey et al., 2012) was completed $15 \mathrm{~h}$ before the ingestion of a high-fat milkshake. Further research is required to establish the influence of energy expenditure or the presence of an energy expenditure threshold in adolescent boys. Postprandial endothelial function appears to be more sensitive to vigorous-intensity exercise (Tyldum et al., 2009). Therefore, the substantial increase in vigorous-intensity exercise but smaller increase in total energy expenditure could explain why endothelial dysfunction was attenuated, but a smaller than 
expected and non-significant effect on postprandial triacylglycerol concentrations was evident, following the accumulated exercise.

It has previously been hypothesised that prior exercise protects against postprandial endothelial dysfunction by lowering postprandial triacylglycerol concentrations (Gill et al., 2004), as a number of studies have reported significant correlations between some quantification of postprandial triacylglycerol concentrations and endothelial dysfunction (Wallace et al., 2010). However, not all studies have reported significant correlations (Johnson et al., 2011; Rudolph et al., 2007; Sedgwick et al., 2012) and this was also the case in the present study. This discrepancy in findings may be due to differences in the methods used to quantify variables (e.g. absolute postprandial values, postprandial changes, total area under the variable versus time curve and incremental area under the concentration time curve), differences in the timing of postprandial events and differences in the lipid load (Wallace et al., 2010; Johnson et al., 2011). In addition many studies that have previously reported significant correlations between postprandial FMD and triacylglycerol concentration responses have pooled the data from a high-fat test meal trial and a low-fat test meal trial, by doing so the range of values within the data set was increased enhancing the chance of finding significant correlations (Bates et al., 1996). Importantly, the present study observed a significant attenuation of postprandial endothelial dysfunction, despite no significant reduction in postprandial triacylglycerol concentrations following the accumulated exercise. This observation provides additional support for the suggestion that exercise-induced alterations in postprandial endothelial function may be independent of changes in postprandial triacylglycerol concentrations (Gill et al., 2004; Tyldum et al., 2009).

This study did not investigate the mechanisms through which accumulated exercise attenuated the postprandial endothelial dysfunction evident in the control trial but there are a number of potential explanations. FMD is a marker of nitric oxide bioavailability (Corretti et al., 2002), with an increase in the inactivation of nitric oxide and/or a decrease in the production of nitric oxide likely to reduce FMD. It is currently believed that a transient rise in oxidative stress, following a high-fat meal, induces a postprandial endothelial dysfunction (Wallace et al., 2010) through free radicals ability to inactivate nitric oxide (Beckman and Koppenol, 1996). Prior exercise may reduce the postprandial rise in oxidative stress by increasing the body's antioxidant capacity, consequently reducing the inactivation of nitric oxide, and so attenuating the decline in FMD (Tyldum et al., 2009). 
In conclusion accumulating a total of $60 \mathrm{~min}$ of exercise through a series of $10 \mathrm{~min}$ exercise bouts spread throughout a day, prior to the consumption of a high-fat breakfast and lunch, attenuated postprandial endothelial dysfunction in adolescent boys.

\section{Perspectives}

Endothelial dysfunction has been implicated in the early stages of atherosclerosis (Ross, 1999) and there is evidence that atherosclerotic development and progression is dependent on the presence of endothelial dysfunction (Juonala et al., 2004). Therefore, any intervention that alters endothelial function could have clinical relevance. The findings of the present study provide experimental support for the concept of accumulating physical activity for good health in young people (World Health Organisation, 2010). Previous research has observed that physical activity completed either in prolonged sessions or accumulated in short bouts have similar positive effects on a child's coronary heart disease risk profile (Stone et al., 2009). Accumulated exercise may be a particularly attractive activity pattern for young people who often perceive prolonged activity to be more exerting than adults (Timmons et al., 2003); it may also have considerable practical utility as shorts bouts of exercise may be relatively easy to incorporate into a school day. The exercise could include activities such as skipping, climbing stairs, circuit type exercises, or power / race walking around playgrounds or between classes / lessons.

\section{Acknowledgements}

We would like to thank all the boys who participated in this study along with their parents/guardians/care givers for their support throughout the study. We would also like to thank the staff at Woodbrook Vale High School in particular Mr Ian Smith for their support. The authors report no conflict of interest. The present study received no specific grant from any funding agency in the public, commercial or not-for-profit sectors. 


\section{References}

Bansal S, Buring JE, Rifai N, Mora S, Sacks FM, Ridker PM. Fasting compared with nonfasting triglycerides and risk of cardiovascular events in women. JAMA. 2007: 298: 309316.

Barrett LA, Morris JG, Stensel DJ, Nevill ME. Exercise and postprandial plasma triacylglycerol concentrations in healthy adolescent boys. Med Sci Sports Exerc. 2007: 39: 116122.

Bates BT, Zhang S, Dufek JS, et al. The effects of sample size and variability on the correlation coefficient. Med Sci Sports Sci. 1996: 28: 386-391.

Beckman JS, Koppenol WH. Nitric oxide, superoxide, and peroxynitrite: the good, the bad, and ugly. Am J Physiol. 1996: 271: c1424-1437.

Borg GA. Perceived exertion: a note on "history" and methods. Med Sci Sports Exerc. 1973: 5: 90-93.

Corretti MC, Anderson TJ, Benjamin EJ, et al. Guidelines for the ultrasound assessment of endothelial-dependent flow-mediated vasodilation of the brachial artery: a report of the International Brachial Artery Reactivity Task Force. J Am Coll Cardiol. 2002: 39: 257-265.

Frayn KN. Calculation of substrate oxidation rates in vivo from gaseous exchange. $J$ Appl Physiol. 1983: 55: 628-634.

Freedson PS, Sirard J, Debold E et al. Calibration of the Computer Science and Applications, Inc. (CSA) accelerometer. Med Sci Sports Exerc. 1997: 29: S45.

Gill JM, Al-Mamari A, Ferrell WR et al. Effects of prior moderate exercise on postprandial metabolism and vascular function in lean and centrally obese men. J Am Coll Cardiol. 2004: 44: 2375-2382. 
Gill JM, Caslake MJ, McAllister C et al. Effects of short-term detraining on postprandial metabolism, endothelial function, and inflammation in endurance trained men: dissociation between changes in triglyceride metabolism and endothelial function. J Clin Endocrinol Metab. 2003: 88: 4328-4335.

Gill JM, Hardman AE. Exercise and postprandial lipid metabolism: an update on potential mechanisms and interactions with high-carbohydrate diets (review). J Nutr Biochem. 2003: 14: 122-132.

Gill JM, Murphy MH, Hardman AE. Postprandial lipemia: effects of intermittent versus continuous exercise. Med Sci Sports Ex. 1998: 30: 1515-1520.

Johnson BD, Padilla J, Harris RA, Wallace JP. Vascular consequences of a high-fat meal in physically active and inactive adults. Appl Physiol Nutr Metab. 2011: 36: 368-375.

Juonala M, Viikari JS, Laitinen T, et al. Interrelations between brachial endothelial function and carotid intima-media thickness in young adults: the cardiovascular risk in young Finns study. Circulation. 2004: 110: 2918-2923.

Harris RA, Nishiyama SK, Wray DW, Richardson RS. Ultrasound assessment of flowmediated dilation. Hypertension. 2010: 55: 1075-1085.

Langsted A, Freiberg JJ, Tybjaerg-Hansen A, et al. Nonfasting cholesterol and triglycerides and association with risk of myocardial infarction and total mortality: the Copenhagen City Heart Study with 31 years of follow up. J Intern Med. 2011: 270: 65-75.

MacEneaney OJ, Harrison M, O'Gorman DJ, Pankratieva EV, O’Connor PL, Moyna NM. Effect of prior exercise on postprandial lipemia and markers of inflammation and endothelial activation in normal weight and overweight adolescent boys. Eur J Appl Physiol. 2009: 106: 721-729.

Magnussen CG, Niinikoski H, Juonala M, et al. When and how to start prevention of atherosclerosis? Lessons from the Cardiovascular Risk in the Young Finns Study and the Special Turku Coronary Risk Factor Intervention Project. Pediatr Nephrol. 2012: 27: 14411452 . 
Maraki M, Sidossis LS. Effects of energy balance on postprandial triacylglycerol metabolism. Curr Opin Clini Nutr Metab Care. 2010: 13: 608-617.

Matthews DR, Hosker JP, Rudenski AS, Naylor BA, Treacher DF, Turner RC. Homeostasis model assessment: insulin resistance and beta-cell function from fasting plasma glucose and insulin concentrations in man. Diabetologia. 1985: 28: 412-419.

Mirwald RL, Baxter-Jones AD, Bailey DA, Beunen GP. An assessment of maturity from anthropometric measurements. Med Sci Sports Exerc. 2002: 34: 689-694.

Miyashita M, Burns SF, Stensel DJ. Accumulating short bouts of brisk walking reduces postprandial plasma triacylglycerol concentrations and resting blood pressure in healthy young men. Am J Clin Nutr. 2008: 88: 1225-1231.

Miyashita M, Burns SF, Stensel DJ. Exercise and postprandial lipemia: effect of continuous compared with intermittent activity patterns. Am J Clin Nutr. 2006: 83: 24-29.

Morrison JA, Glueck CJ, Horn PS, et al. Pediatric triglycerides predict cardiovascular disease events in the fourth to fifth decade of life. Metabolism. 2009: 58: 1277-1284.

Nordestgaard BG, Benn M, Schnohr P, et al. Nonfasting triglycerides and risk of myocardial infarction, ischemic heart disease, and death in men and women. JAMA. 2007: 298: 299-308.

Peddie MC, Rehrer NJ, Perry TL. Physical activity and postprandial lipidemia: are energy expenditure and lipoprotein lipase activity the real modulators of the positive effect? Prog Lipid Res. 2012: 51: 11-22.

Petitt DS, Cureton KJ. Effects of prior exercise on postprandial lipemia: a quantitative review. Metabolism. 2003: 52: 418-424.

Ross R. Atherosclerosis-an inflammatory disease. N Engl J Med. 1999: 340: 115-126. 
Rudolph TK, Ruempler K, Schwedhelm E, et al. Acute effects of various fast-food meals on vascular function and cardiovascular disease risk markers: the Hamburg Burger Trial. Am J Clin Nutr. 2007: 86: 334-340.

Sedgwick MJ, Morris JG, Nevill ME, Tolfrey K, Nevill A, Barrett LA. Effect of exercise on postprandial endothelial function in adolescent boys. $B r \quad J$ Nutr. 2012: doi:10.1017/S0007114512004977.

Stone MR, Rowlands, AV, Middlebrooke AR, Jawis MN, Eston RG. The pattern of physical activity in relation to health outcomes in boys. Int J Pediatr Obes. 2009: 4: 306-315.

Strong JP, Gill HC. The natural history of coronary atherosclerosis. Am J Pathol. 1962: 40: 3749.

Tanner JM. Foetus into Man: Physical Growth from Conception to Maturity, 2nd ed. Ware, UK: Castlemead Publications: 1989. 213 p.

Taveras EM, Berkey CS, Rifas-Shiman SL, et al. Association of consumption of fried food away from home with body mass index and diet quality in older children and adolescents. Pediatrics. 2005: 116: e518-524.

Thijssen DH, Black MA, Pyke KE, et al. Assessment of flow-mediated dilation in humans: a methodological and physiological guideline. Am J Physiol Heart Circ Physiol. 2011: 300: h212.

Timmons BW, Bar-Or O. RPE during prolonged cycling with and without carbohydrate ingestion in boys and men. Med Sci Sports Exerc. 2003: 35: 1901-1907.

Tolfrey K, Bentley C, Goad M, Varley J, Willis S, Barrett L. Effect of energy expenditure on postprandial triacylglycerol in adolescent boys. Eur J Appl Physiol. 2012: 112: 23-31.

Tolfrey K, Doggett A, Boyd C, Pinner S, Sharples A, Barrett L. Postprandial triacylglycerol in adolescent boys: a case for moderate exercise. Med Sci Sports Exerc. 2008: 40: 1049-1056. 
Trost SG, Ward DS, Moorehead SM, Watson PD, Riner W, Burke JR. Validity of the computer science and applications (CSA) activity monitor in children. Med Sci Sports Exerc. 1998: 30: 629-633.

Tyldum GA, Schjerve IE, Tjonna AE et al. Endothelial dysfunction induced by post-prandial lipemia: complete protection afforded by high-intensity aerobic interval exercise. J Am Coll Cardiol. 2009: 53: 200-206.

Vogel RA, Corretti MC, Plotnick GD. Effect of a single high-fat meal on endothelial function in healthy subjects. Am J Cardiol. 1997: 79: 350-354.

Wallace JP, Johnson B, Padilla J, Mather K. Postprandial lipaemia, oxidative stress and endothelial function: a review. Int J Clin Pract. 2010: 64: 389-403.

Williams C, Nute MLG. Some physiological demands of a half-marathon race on recreational runners. Br J Sports Med. 1983: 17: 152-161.

World Health Organization. Global Recommendations on Physical Activity for Health. Geneva, Switzerland. 2010: 20 p.

Yeboah J, Folsom AR, Burke GL, et al. Predictive value of brachial flow-mediated dilation for incident cardiovascular events in a population-based study: the multi-ethnic study of atherosclerosis. Circulation. 2009: 120: 502-509.

Zilversmit DB. Atherogenesis: a postprandial phenomenon. Circulation. 1979: 60: 473-485. 
Table 1: Physical characteristics of participants

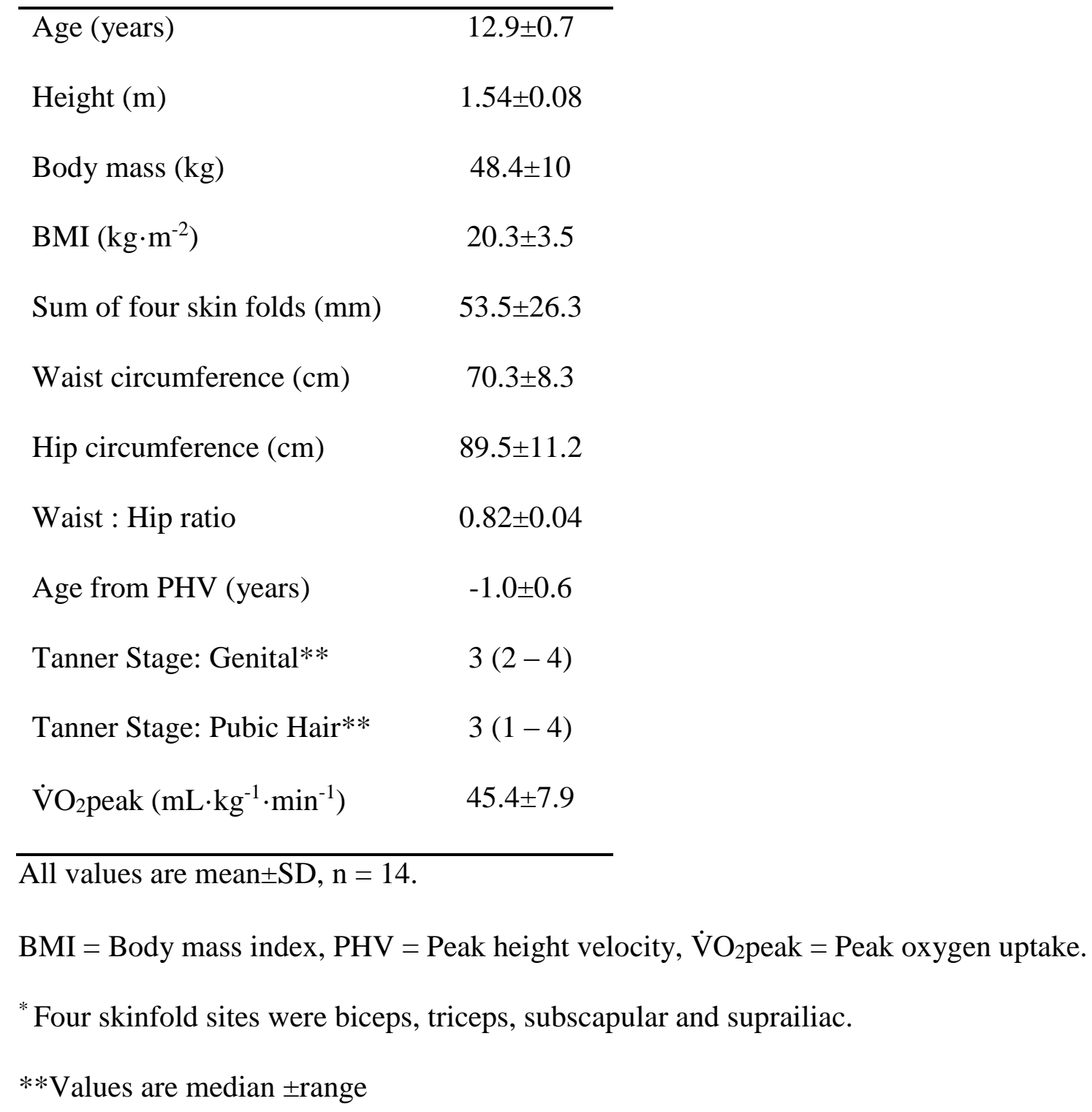


Table 3. Basal diameter and peak diameter of the brachial artery during the measurement of flow-mediated dilation in the control and exercise trials*

\begin{tabular}{lcccccc}
\hline & \multicolumn{3}{c}{ Control } & \multicolumn{3}{c}{ Exercise } \\
\cline { 2 - 7 } & $0 \mathrm{~h}$ & $3 \mathrm{~h}$ & $6.5 \mathrm{~h}$ & $0 \mathrm{~h}$ & $3 \mathrm{~h}$ & $6.5 \mathrm{~h}$ \\
\hline Basal diameter $(\mathrm{mm}) \dagger+$ & $3.12 \pm 0.08$ & $3.24 \pm 0.08$ & $3.27 \pm 0.08$ & $3.14 \pm 0.09$ & $3.20 \pm 0.10$ & $3.23 \pm 0.09$ \\
Peak diameter (mm) + & $3.38 \pm 0.08$ & $3.43 \pm 0.08$ & $3.46 \pm 0.08$ & $3.40 \pm 0.09$ & $3.46 \pm 0.10$ & $3.49 \pm 0.09$ \\
\hline
\end{tabular}

All values are mean \pm SEM; $\mathrm{n}=13$.

*Data was analysed using a mixed effects general linear model with two fixed factors (trial and time and one random factor (participant: for both basal and peak diameter: main effect trial $P>0.05$; main effect trial $P<0.05$; interaction effect trial $\mathrm{x}$ time, $P>0.05$. Least significant differences was used to identify where significant main effects lay.

$\uparrow$ Main effect - time: Difference between $0 \mathrm{~h}$ and $3.5 \mathrm{~h}, P<0.05$

$\$$ Main effect - time: Difference between $0 \mathrm{~h}$ and $6.5 \mathrm{~h}, P<0.05$ 
(a)

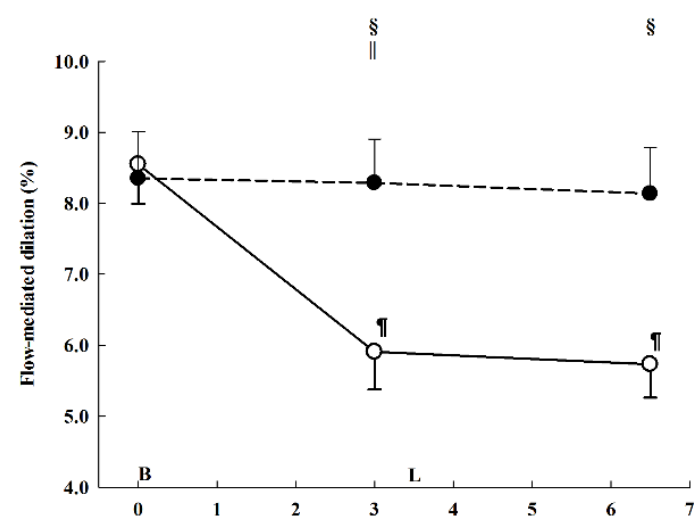

(b)

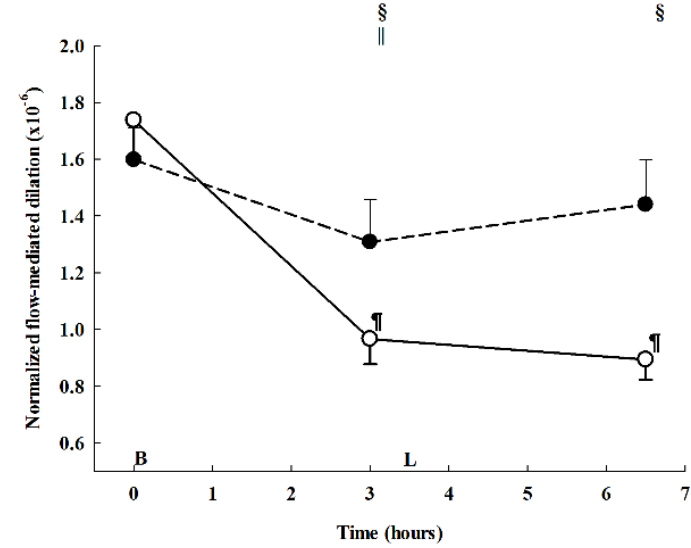

Fig. 1. (a) Flow-mediated dilation and (b) normalised flow-mediated dilation. B, breakfast: $L$, lunch. Values are means, with their standard errors represented by vertical bars $(n=13)$. Data were analysed using a mixed-effects general linear model with two fixed factors (trial and time) and one random factor (participant). Least significant differences post-hoc analysis was used to identify where significant main effects lay and when a significant time $x$ trial interaction was identified, pre-specified planned comparisons were used, specifically, comparisons within trial with respect to the fasting measure and between trials at the same time point. (a) Flow-mediated dilation: main effect trial, $\mathrm{P}=0.004$ : main effect time, $\mathrm{P}<0.001$ : interaction effect trial $\mathrm{x}$ time, $\mathrm{P}<0.001$. (b) Normalised flow-mediated dilation: main effect trial, $P=0.020$ : main effect time, $P<$ 0.001: interaction effect trial $x$ time, $P=0.014$. $\S$ post-hoc analysis on main effect of time - difference from $0 \mathrm{~h}, \mathrm{P}<0.05$ : || post-hoc analysis on main effect of time - difference from previous time point, $P<0.05$ : II post-hoc analysis on interaction effect trial $x$ time difference from $0 \mathrm{~h}$ in the same trial and difference from exercise trial at same time point, $\mathbf{P}<\mathbf{0 . 0 5}$.

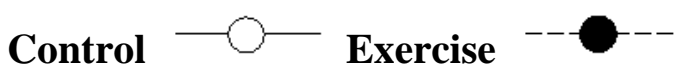



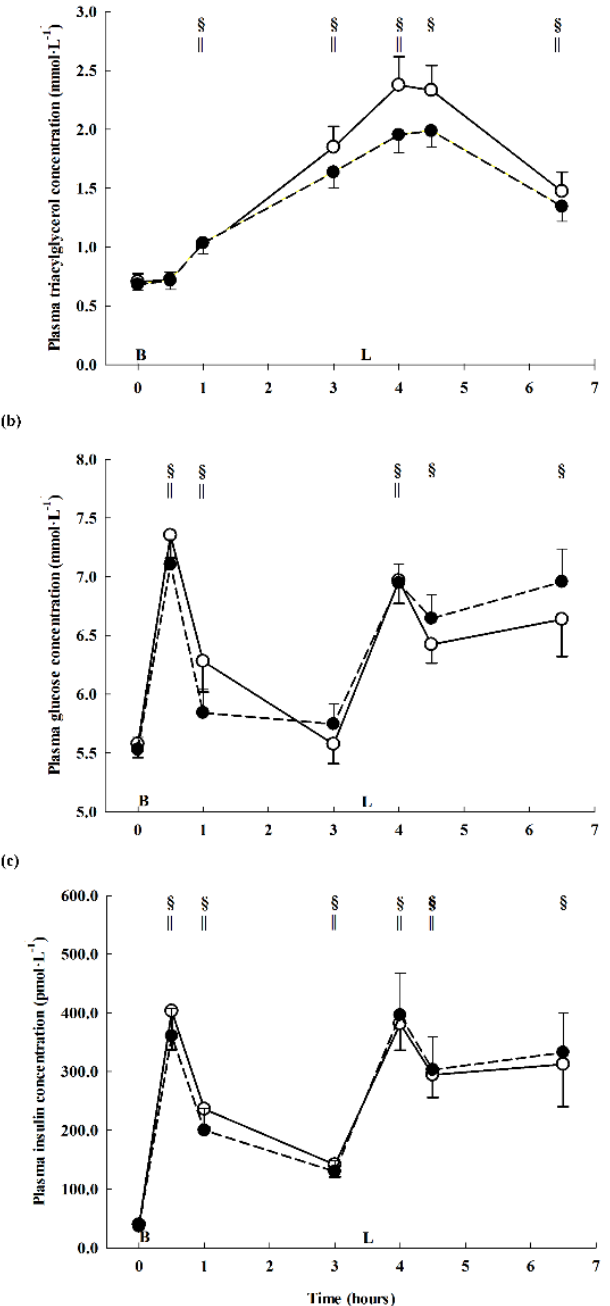

Fig. 2. Plasma (a) triacylglycerol (b) glucose (c) insulin concentrations. B, breakfast: $L$, lunch. Values are means, with their standard errors represented by vertical bars $(n=$ 14). Data were analysed using a mixed-effects general linear model with two fixed factors (trial and time) and one random factor (participant). Least significant differences posthoc analysis was used to identify where significant main effects lay: triacylglycerol data were Ln transformed prior to the analysis. (a) Triacylglycerol: main effect trial, $P=0.385$ : main effect time, $P<0.001$ : interaction effect trial $x$ time, $P=0.091$. (b) Glucose: main effect trial, $P=0.916$ : main effect time, $P<0.001$ : interaction effect trial $\mathrm{x}$ time, $P=0.066$. (c) Insulin: main effect trial, $P=0.435$ : main effect time, $P<0.001$ : interaction effect trial $\mathrm{x}$ time, $P=0.515$. $\S$ post-hoc analysis on main effect of time - difference from $0 \mathrm{~h}, \mathrm{P}<0.05$ : |l post-hoc analysis on main effect of time - difference from previous time point, $P<0.05$. Control Exercise 